\title{
PREVALENCE OF DENTAL FLUOROSIS IN BAURU, SÃO PAULO, BRAZIL
}

\author{
Irene RAMIRES ${ }^{1}$, Juliano Pelim PESSAN² Flávia Mauad LEVY³ $^{3}$, Maria Heloísa Correia RODRIGUES ${ }^{3}$, \\ Beatriz Simões de ALMEIDA ${ }^{4}$, Melissa Thiemi KATO ${ }^{5}$, Silvia Helena de Carvalho SALES PERES ${ }^{6}$, Marília Afonso Rabelo BUZALAF ${ }^{7}$
}

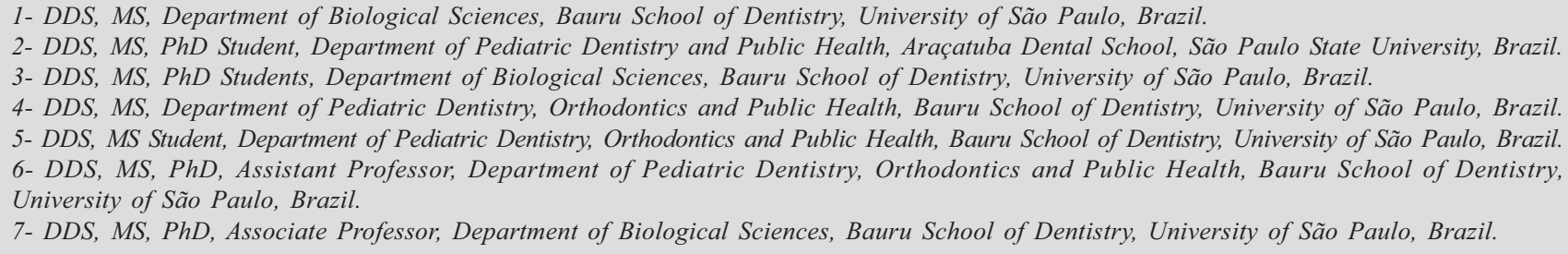

Corresponding address: Marília Afonso Rabelo Buzalaf - Bauru School of Dentistry - University of São Paulo - Department of Biological Sciences (Biochemistry) - Al. Dr. Octávio Pinheiro Brisolla, 9-75 - Bauru-SP, Brazil - 17012-901 - Phone: 551432358346 - e-mail: mbuzalaf@fob.usp.br

Received: December 04, 2006 - Modification: February 09, 2007 - Accepted: March 15, 2007

\begin{abstract}
$O$

bjective: To evaluate the prevalence of dental fluorosis in scholars aging 12 to 15 years old, residents in the city of Bauru, State of São Paulo, Brazil. Methods: 1318 volunteers were enrolled in this study and examined in 18 public schools of the State of São Paulo. The examinations were performed in the schools' court by three dentists (with a Master's degree in Public Health), after toothbrushing supervised by another dentist. The teeth were dried with cotton pellets and examined under natural light by visual inspection, using an explorer as recommended by the WHO, a plane mirror and a tongue depressor. The Thylstrup-Fejerskov (TF) index was used for rating fluorosis. Intra and inter-examiner reproducibility was calculated and data were submitted to descriptive analysis. Results: Approximately $36 \%$ of the children presented dental fluorosis, of which $28 \%$ was diagnosed as TF1 while the remaining received scores between TF2 and TF4. Conclusion: The prevalence of dental fluorosis in Bauru is within the expected range, based on previous studies. Although fluoride is an important resource for caries control, its use must be adequate to the needs of each specific population.
\end{abstract}

Uniterms: Fluoride; Dental fluorosis; Epidemiology.

\section{INTRODUCTION}

Fluoride is considered as an important resource for the control of dental caries. The effect of this element on the dentition is dose-dependent. However, above certain levels of fluoride exposure regarded as adequate, considering all sources of intake, visible changes in dental structure, mainly in enamel, become evident. This condition is known as dental fluorosis. It is important to emphasize that dental fluorosis is expected to occur only in case of excessive and prolonged fluoride ingestion during the period of dental development, i.e., during amelogenesis ${ }^{1,3,4,10}$. Therefore, it is possible to establish a susceptible period to dental fluorosis, depending on individual variations on the amelogenesis period. For permanent teeth, this period ranges from birth to 6 years of age $^{13}$.

Some teeth are more affected than others. Posterior teeth are usually more severely compromised in areas with high fluoride concentrations in the drinking water. On the other hand, in areas with moderate fluoride concentrations in water, premolars are the most commonly affected teeth together with incisors. In the permanent dentition, the pattern of fluorosis risk distribution is as follows: premolars $>$ second molars $>$ upper incisors $>$ canines $>$ first molars $>$ lower incisors. This sequence may vary, as some studies have reported that the incisors are the most affected teeth ${ }^{2,14}$.

Clinically, dental fluorosis appears in different forms, depending on the fluoride dose, and the period and duration of tooth exposure during amelogenesis. Post-eruptive enamel staining is an important aspect to be considered because it is not a direct result of amelogenesis influenced by fluoride, but it is rather of exogenous origin (after tooth eruption). This is one of the negative aspects of some fluorosis indexes that consider the presence of staining when evaluating the severity ${ }^{11}$.

Although different indexes are used to evaluate dental 
fluorosis, some studies have report that the prevalence in Brazil is below $30 \%$ in cities in which fluoride concentration in water is approximately $0.8 \mathrm{mg} / \mathrm{L}^{1,3,6,7,14}$. Higher prevalence rates can be attributed to the synergic effect of dental products, infant formulas and fluoride-containing water. In addition, the wide variation in the prevalence of fluorosis in Brazilian urban areas can partially be attributed to methodological differences among the studies ${ }^{1}$.

Some studies have shown an increase in the prevalence of dental fluorosis during the last years, mainly in the mildest degrees $^{3,7}$. Water has been considered responsible for this increase in $40 \%$ of cases. The remaining $60 \%$ is attributed to other fluoride sources ${ }^{5}$. In the city of Bauru, State of São Paulo, Brazil, in addition to water fluoridation, there are preventive programs in which $\mathrm{NaF}$ solution rinses and supervised toothbrushing with fluoride dentifrices are used. The purpose of the present study was to assess the prevalence of dental fluorosis in 12 to 15 year-old scholars in the city of Bauru, SP.

\section{MATERIAL AND METHODS}

Fluoridation of the public water supply in Bauru started in October 10, 1975, by the Water Treatment Station (WTS). In $1990,100 \%$ of the water supplied by the Water and Sewerage System Department (WSSD) was chlorinated and fluoridated. In 2004, Bauru had approximately 350,000 habitants, of which $44 \%$ were supplied with water from WTS and the remaining, by 27 artesian wells. Public water in Bauru has been fluoridated based on the average of the higher daily temperatures $\left(26^{\circ} \mathrm{C}\right)$, indicating that the ideal fluoride concentration for this city was $0.7 \mathrm{mg} / \mathrm{L}$.

\section{Epidemiological Surveillance}

Prior to performing this transversal study, the project was submitted to and approved by the research ethics committee of Bauru School of Dentistry, University of São Paulo. A group of 1,318 schoolchildren of both genders, aged between 12 and 15 years, was examined after obtaining authorization from the persons responsible for them. According to the inclusion criteria, the subjects should be available to participate in the study, belong to the established age group and have been born in the district in which the study was conducted. The examinations were performed in 18 schools (the total of schools encompassing this age range is 27) between September and October, 2004.

The examinations were performed in schools' court by three dentists (with a Master's degree in Public Health), after toothbrushing supervised by another dentist. The teeth were dried with cotton pellets and the examinations were done under natural light by visual inspection, using an explorer as recommended by the World Health Organization (WHO), a plane mirror and a tongue depressor. During the examinations, the volunteers were seated on chairs.

All buccal surfaces were examined and the ThylstrupFejerskov (TF) index was used for rating fluorosis ${ }^{13}$. Teeth with restorations or with less than $2 / 3$ of the crowns erupted were not examined. The degree of fluorosis was determined using the highest score recorded for each volunteer.

\section{Statistical analysis}

Descriptive analysis of the data obtained was done using the SPSS software. Kappa test was done to assess inter $(0.76)$ and intra-examiner $(0.67)$ reproducibility.

\section{RESULTS}

Dental fluorosis was detected in approximately $36 \%$ of the volunteers examined $(n=1318)$, of which $28 \%$ was diagnosed as TF1 score $(n=370)$ while the remaining received scores between TF2 and TF4 (Table 1). The prevalence of dental fluorosis was lower in the 15-year-old age group (29.59\%) compared to the others and no significant differences were observed between genders (Table 2). Premolars showed the highest prevalence of dental fluorosis $(17.51 \%)$ as well as the highest prevalence of TF4 score (Table 3).

\section{DISCUSSION}

The results of this study corroborated the findings of previous investigations conducted in areas with artificially fluoridated water ${ }^{1,3,6,7,14}$. Although the prevalence of fluorosis observed in the present study (35.58\%) was slightly higher than that reported in studies in which the water presented similar fluoride concentrations (ranging from 0.6 and $0.8 \mathrm{mg}$ $\mathrm{F} / \mathrm{L}$ ), this is not relevant in terms of public health because $28 \%$ of the volunteers presented dental fluorosis rated as TF1 score. The prevalence of fluorosis in Bauru was very close to that reported by other investigators in the cities of Piratininga $(34.44 \%)^{14}$ and Piracicaba $(31 \%)^{7}$, as well as in a peripheral district of Bauru $(33 \%)^{8}$. A highest prevalence of TF1 score was also found in these studies ${ }^{7,8}$. It is noteworthy that, regarding the severity of dental fluorosis, cases rated with the lowest scores tend to disappear or at least become less pronounced, due to physiological enamel wear, because dental fluorosis in the mildest degrees affects only the most superficial layers of enamel ${ }^{6}$.

Regarding the small difference in the prevalence of fluorosis between genders, this result was, in fact, expected,

TABLE 1- Prevalence of dental fluorosis in scholars aging 12 to 15 years old in Bauru, São Paulo, 2004

\begin{tabular}{cll}
\hline Fluorosis scores (TF index) & $\boldsymbol{n}$ & $\%$ \\
\hline 0 & 849 & 64.42 \\
1 & 370 & 28.08 \\
2 & 69 & 5.24 \\
3 & 24 & 1.82 \\
4 or $>$ & 6 & 0.46 \\
\hline
\end{tabular}


because the same pattern has been described in a previous study $^{3}$. Concerning the different dental groups, the highest prevalence found for premolars was also expected and confirms results from other studies. The lag time for amelogenesis in premolars is larger than for other dental groups, which makes them more exposed to the action of fluoride ${ }^{2,13}$. In addition, when comparing different studies, it is important to take into account the age range of the volunteers examined. In a study by Maltz, et al. ${ }^{6}(2000)$, the highest prevalence of dental fluorosis was observed for upper central incisors and lower first molars; however, in that study the volunteers were 8-9 years old.

Therefore, isolated cases in which a higher severity was observed can be related to the association of different sources of fluoride intake, and not to fluoridated water itself. These patients should be regarded and followed up by the epidemiological surveillance, in order to control the occurrence of new cases. It is important to have a rigorous control of oral health educative and preventive programs that indicate rinses with fluoridated solutions or supervised toothbrushing with fluoride dentifrice. These fluoride vehicles have been repeatedly shown to be effective and safe, but special attention must be given especially to young children, who can swallow fluoride from these sources. In this sense, another important action is the monitoring of public water fluoride concentrations. In Bauru, this monitoring started in 2004 (the same year in which the present study was done) and has been conducted by the Biochemistry Laboratory of Bauru School of Dentistry, University of São Paulo. Since its implementation, significant improvement has been achieved in the quality of the water regarding its fluoride concentrations ${ }^{9}$.

Although fluoride is considered as an important resource for caries control, its use must be adequate to the needs of each specific population, for an accurate and effective control of dental caries and prevention of dental fluorosis.

\section{REFERENCES}

1- Cangussu MCT, Narvai PC, Fernandez RC, Djehizian V. A fluorose dentária no Brasil: uma revisão crítica. Cad Saude Publica. $2002 ; 18(1): 7-15$.

2- Dummer PMH, Kingdon A, Kingdom R. Distribution of developmental defects od tooth enamel by tooth-type in 11-12year-old children in South Wales. Community Dent Oral Epidemiol. 1986;14:341-4.

3- Forte FDS, Freitas CHSM, Sampaio FC, Jardim MCAM. Fluorose dentária em crianças de Princesa Isabel, Paraíba. Pesqui Odontol Bras. 2001;15(2):87-90.

TABLE 2- Distribution of dental fluorosis according to age and gender, and total of scholars examined in Bauru, 2004

\begin{tabular}{lllcl}
\hline Age & $\begin{array}{c}\text { Gender } \\
\text { Male }(\mathbf{n})\end{array}$ & $\begin{array}{c}\text { Gender } \\
\text { Female }(\mathbf{n})\end{array}$ & $\begin{array}{c}\text { \% of subjects presenting } \\
\text { fluorosis }(\boldsymbol{n})\end{array}$ & $\begin{array}{c}\boldsymbol{n} \text { total of scholars } \\
\text { examined }\end{array}$ \\
\hline 12 & $39.31(68)$ & $35.43(62)$ & $37.36(130)$ & 348 \\
13 & $38.04(62)$ & $41.28(71)$ & $39.70(133)$ & 335 \\
14 & $34.59(64)$ & $35.26(55)$ & $34.90(119)$ & 341 \\
15 & $27.59(40)$ & $31.54(47)$ & $29.59(87)$ & 1318 \\
Total & & & $35.58(469)$ &
\end{tabular}

TABLE 3- Percent distribution of dental fluorosis (TF index) according to severity in the different dental groups of the scholars of Bauru, 2004

\begin{tabular}{|c|c|c|c|c|c|c|c|c|}
\hline \multirow[t]{2}{*}{ Dental group } & & \multicolumn{6}{|c|}{ Percent means of dental fluorosis (TF index) } & \multirow[t]{2}{*}{$n$ total } \\
\hline & & 0 & 1 & 2 & 3 & 4 & $>4$ & \\
\hline \multirow[t]{2}{*}{ Incisors } & Upper & 92.86 & 6.17 & 0.80 & 0.15 & 0.02 & - & 5272 \\
\hline & Lower & 95.66 & 4.10 & 0.25 & - & - & - & 5272 \\
\hline \multirow[t]{2}{*}{ Canines } & Upper & 91.31 & 7.09 & 1.40 & 0.04 & 0.08 & 0.08 & 2636 \\
\hline & Lower & 93.66 & 5.31 & 0.91 & 0.08 & 0.04 & - & 2636 \\
\hline \multirow[t]{2}{*}{ Premolars } & Upper & 78.83 & 17.24 & 3.11 & 0.65 & 0.15 & 0.02 & 5272 \\
\hline & Lower & 86.15 & 11.53 & 1.92 & 0.28 & 0.12 & - & 5272 \\
\hline \multirow[t]{2}{*}{ Molars } & Upper & 86.57 & 11.52 & 1.59 & 0.28 & 0.04 & - & 5272 \\
\hline & Lower & 88.88 & 9.85 & 1.00 & 0.19 & 0.08 & - & 5272 \\
\hline
\end{tabular}

TF index = Thylstrup-Fejerskov index. 
4- Hellwig E, Lennon AM. Systemic versus topical fluoride. Caries Res. 2004;38:258-62

5- Lewis DW, Banting DW. Water fluoridation: current effectiveness and dental fluorosis. Community Dent Oral Epidemiol.1994;22(3):153-8

6- Maltz M, Silva BB, Schaeffer A, Farias C. Prevalência de fluorose dentária em duas cidades brasileiras, uma com água artificialmente fluoretada e outra com baixo teor de flúor, em 1987 e 1997/98. Rev Fac Odontol Porto Alegre. 2000;42(2):52-5.

7- Pereira AC, Mialhe FL, Bianchini FLC, Meneghim MC. Prevalência de cárie e fluorose dentária em escolares de cidades com diferentes concentrações de flúor na água de abastecimento. Rev Bras Odontol Saude Coletiva. 2001;2(1):34-9.

8- Ramires I, Olympio KPK, Maria AG, Pessan JP, Cardoso VES Lodi CS, et al. Fluoridation of the public water supply and prevalence of dental fluorosis in a peripheral district of the municipality of Bauru, SP. J Appl Oral Sci. 2006;14(2):136-41.

9- Ramires I, Maia LP, Rigolizzo DS, Lauris JRP, Buzalaf MAR. External control of the fluoridation of the public water supply in Bauru, SP, Brazil. Rev Saude Publica. 2006;40(5):883-9.

10- Robinson C, Connell S, Kirkham J, Brookes SJ, Shore RC, Smith AM. The effect of fluoride on the developing tooth. Caries Res. 2004;38:268-76.

11 - Rozier RG. Epidemiologic indices for measuring the clinical manifestations of dental fluorosis: overview and critique. Adv Dent Res. 1994;8:39-55.

12- Sampaio FC, Ramm von der Fehr F, Arneberg P, Petrucci Gigante D, Hatloy A. Dental fluorosis and nutritional status of 6- to 11-yearold children living in rural areas of Paraíba, Brazil. Caries Res. 1999;33:666-73.

13- Thylstrup A, Fejerskov O. Clincial appearance of dental fluorosis in permanent teeth in relation to histologic changes. Community Dent Oral Epidemiol. 1978;6:315-28.

14- Tomita NE, Panighel CPMA, Narvai PC, Lopes ES. Implicações da vigilância à saúde sobre a ocorrência de fluorose dental. Rev ABO Nac. 1995;3:318-23 